\title{
Visual Diagnosis: A Young Woman with Acute Abdominal Pain
}

\author{
Talib Dosani1, Lars Beattie ${ }^{2}$, Matthew F. Ryan ${ }^{2 *}$ \\ ${ }^{1}$ Department of Medicine, University of Florida, Gainesville, FL, USA \\ ${ }^{2}$ Department of Emergency Medicine, University of Florida, Gainesville, FL, USA \\ Email: *mfryan@ufl.edu
}

How to cite this paper: Dosani, T., Beattie, L. and Ryan, M.F. (2017) Visual Diagnosis: A Young Woman with Acute Abdominal Pain. Open Journal of Emergency Medicine, 5, 8-12.

https://doi.org/10.4236/ojem.2017.51002

Received: February 12, 2017

Accepted: March 14, 2017

Published: March 17, 2017

Copyright (c) 2017 by authors and Scientific Research Publishing Inc. This work is licensed under the Creative Commons Attribution International License (CC BY 4.0).

http://creativecommons.org/licenses/by/4.0/

\begin{abstract}
A 27-year-old female with a history of Crohn's disease and familial adenomatous polyposis (FAP) presented to the emergency department (ED) with severe abdominal pain after an endoscopic exam. Chest and abdominal radiographs revealed massive pneumoperitoneum and the patient underwent emergent exploratory surgery. Herein, we discuss the management and outcomes of this case. The importance of a thorough history and physical exam when evaluating for an acute abdomen and thus the development of a successful management plan is also underscored.
\end{abstract}

\section{Keywords}

Iatrogenic Perforations, Pneumoperitoneum, Endoscopic Procedure, Emergent Surgery

\section{Introduction}

Iatrogenic perforations are an uncommon but clinically and potentially catastrophic complication of endoscopic procedures. The incidence of iatrogenic perforations is thought to be increasing because of the expanded use of endoscopic screening programs and the widening array indications for endoscopic procedures [1]. Immediate identification and emergent surgical consultation are needed and a delay in care may result in rapid patient demise. It is imperative that the emergency medicine physician be eminently aware of the risks of postprocedural iatrogenic perforations and mobilizes all requisite resources without hesitation. We describe a case of iatrogenic perforation where the patient without emergent intervention would have likely succumbed to her condition. The case presentation herein provides a framework for our discussion of the state of the art care for such patients and describes what the physician needs to know in 
order to manage such emergent cases.

\section{Case Presentation}

A 27-year-old female with a history of Crohn's disease and familial adenomatous polyposis (FAP) presented the emergency department (ED) complaining of debilitating abdominal pain. The patient had undergone surveillance esophagogastroduodenoscopy and pouchoscopy for her chronic condition at an outside facility earlier in the day and had been discharged after an uneventful post-procedural recovery period. Of note, the patient had multiple intestinal resection surgeries stemming from her Crohn's disease and FAP. Upon return home the patient began to have progressively worsening abdominal pain associated with abdominal bloating, nausea, and vomiting.

Upon presentation to the emergency department, the patient appeared toxic and her presenting vital signs revealed a heart rate of 93, blood pressure of $117 / 80$, temperature of $37.7^{\circ} \mathrm{C}$ and respiratory rate of 16 . Her pulse oximetry was $100 \%$ on room air. Physical examination was remarkable for an exquisitely tender rigid abdomen with abdominal guarding. While the patient was afebrile and hemodynamically stable, she appeared quite ill and in distress. Intravenous fluids and antibiotics which included vancomycin, metronidazole and cefepime were immediately administered and the patient was given morphine for analgesia. Labs were significant for a white cell count of 21,000 cell $/ \mathrm{mm}^{3}$ with $86 \%$ neutrophiles and hemoglobin of $11.4 \mathrm{~g} / \mathrm{dL}$. Her electrolytes were within normal limits and her bicarbonate level was $18 \mathrm{mmol} / \mathrm{L}$ with a normal anion gap. The presentation was highly suspicious for a perforated viscous; subsequent chest and abdominal radiographs were obtained emergently and showed massive pneumoperitoneum and dilated bowel in the left abdomen in the region of the prior surgical anastomosis (Figure 1 and Figure 2) confirming our suspicions.

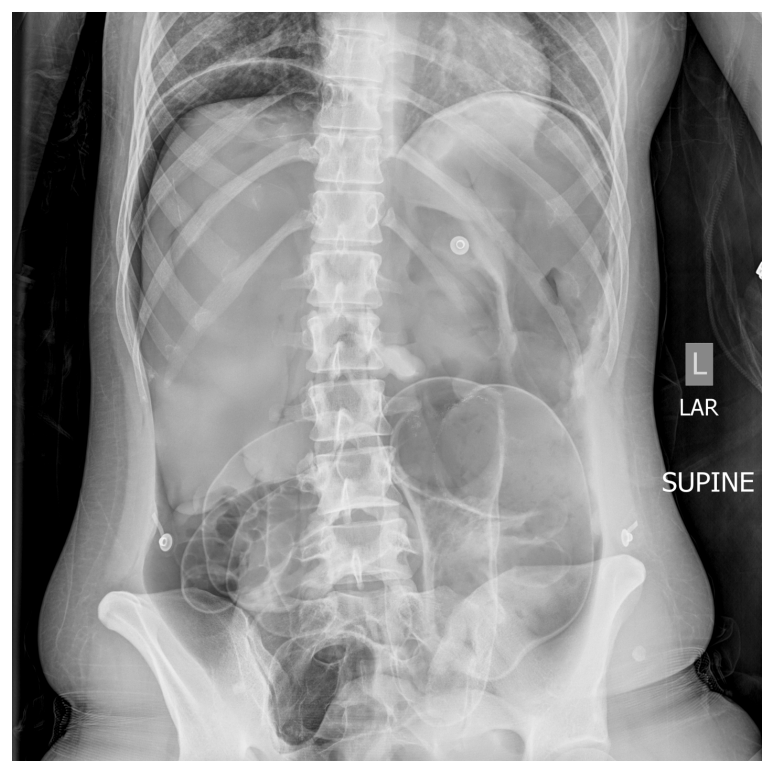

Figure 1. Massive iatrogenic pneumoperitoneum and dilated bowel in the left abdomen in the region of the prior surgical anastomosis post endoscopy. 


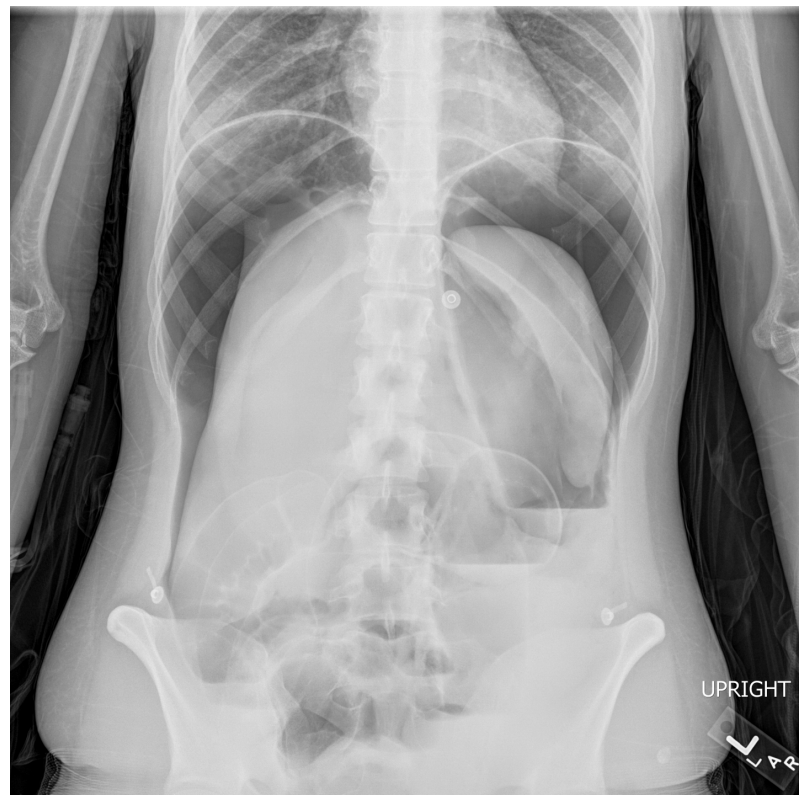

Figure 2. Massive iatrogenic pneumoperitoneum and dilated bowel in the left abdomen post endoscopy.

Emergent surgical consultation was called for evaluation of an enteric perforation status post esophagogastroduodenoscopy and pouchoscopy. Based on the clinical scenario and imaging studies, the patient was taken immediately to the operating room for an exploratory laparotomy and was found to have a dilated enteroenterostomy with air within the mesentery; the site of enteric perforation was discovered and had spontaneously sealed. The patient had an uneventful post-operative course and had a return of bowel function four days after her surgery. The patient was discharged on post-operative day five and has had no subsequent bowel obstructions since.

\section{Discussion}

Iatrogenic perforations are an uncommon but clinically and potentially catastrophic complication of endoscopic procedures. The incidence of iatrogenic perforations is posited to increase simply because of the expanded implementation of endoscopic screening programs and the widening array indications for endoscopic procedures [1]. Moreover, early identification of perforation and immediate intervention significantly improves patient outcomes. For these critical reasons, understanding of the risks of iatrogenic perforations and expedient identification and management of patients who present with abdominal pain after a recent endoscopy is important in the acute-care setting. Such patients require rapid diagnosis and immediate mobilization of resources for definitive care. General care includes following a strict nil per os regimen, intravenous proton pump inhibitors, broad spectrum antibiotics, intravenous fluid resuscitation, pain management and emergent surgical consultation for repair of suspected perforation.

Perforations often go unrecognized at the time of the procedure and physi- 
cians should thus maintain a high suspicion for such complications in post-endoscopy patients [1] [2]. Signs and symptoms are dependent on the site of perforation and often include generalized abdominal pain, nausea, vomiting, anorexia, chest pain, and shortness of breath. Late presentations may additionally include systemic inflammatory response, hypotension, altered mental status, sepsis and fulminant septic shock [1].

Abdominal and chest radiographs may show pneumomediastinum or pneumoperitoneum, as was noted in this case. However, radiographs are poorly sensitive and specific for perforations and are considered sub-optimal to computed tomography scanning, which should be obtained when feasible [3]. Computed tomography can localize the site of perforation of a hollow viscous which is an important key for emergent surgery. Computed tomography can provide details regarding the site of perforation through direct and indirect signs including bowel wall thickening, a localized hollow viscous or bowel wall defect or the presence of extraluminal gas which is likely adjacent to the perforation site.

Management of these patients includes placement of large bore intravenous catheters, rapid fluid resuscitation, intravenous antibiotics and emergent surgical consultation [3]. Surgical consultation should not be delayed as early surgical intervention when indicated, substantially impacts the post-perforation outcome [4]. Our patient underwent an immediate exploratory laparotomy, which revealed the site perforation was the small bowel which had sealed spontaneously. The patient had an uneventful post-surgical course and was discharged after five days without any negative outcomes.

\section{Conclusion}

Perforated viscosity is a serious and life threatening emergency and needs to be diagnosed immediately as this represents a true emergency which requires emergent surgery consulting and intervention. In a climate of advanced technology and increasing medical complexity, thorough history and physical exam skills with a heightened clinical suspicion and vigilance are often better than advanced imaging or laboratory studies. This case was diagnosed clinically and corroborated with a simple abdominal series films.

\section{Conflict of Interest}

The authors declare no conflict of interests.

\section{References}

[1] Paspatis, G.A., et al. (2014) Diagnosis and Management of Iatrogenic Endoscopic Perforations: European Society of Gastrointestinal Endoscopy Position Statement. Endoscopy, 46, 693-711. https://doi.org/10.1055/s-0034-1377531

[2] Anderson, M.L., Pasha, T.M. and Leighton, J.A. (2000) Endoscopic Perforation of the Colon: Lessons from a 10-Year Study. American Journal of Gastroenterology, 95, 3418-3422. https://doi.org/10.1111/j.1572-0241.2000.03356.x

[3] Kowalczy, L. (2011) Algorithm for the Management of Endoscopic Perforations: A 
Quality Improvement Project. American Journal of Gastroenterology, 106, 10221027. https://doi.org/10.1038/ajg.2010.434

[4] Paspatis, G.A. (2008) Complications of Colonoscopy in a Large Public County Hospital in Greece. A 10-Year Study. Digestive and Liver Disease, 40, 951-957. https://doi.org/10.1016/j.dld.2008.02.041

Submit or recommend next manuscript to SCIRP and we will provide best service for you:

Accepting pre-submission inquiries through Email, Facebook, LinkedIn, Twitter, etc. A wide selection of journals (inclusive of 9 subjects, more than 200 journals)

Providing 24-hour high-quality service

User-friendly online submission system

Fair and swift peer-review system

Efficient typesetting and proofreading procedure

Display of the result of downloads and visits, as well as the number of cited articles Maximum dissemination of your research work

Submit your manuscript at: http://papersubmission.scirp.org/

Or contact ojem@scirp.org 